\title{
Chance, Evolution, and the Metaphysical Implications of Paleontological Practice
}

\author{
Alan C. Love
}

\subsection{Evolutionary Metanarratives}

Stories are narratives that connect agents and events in causal relations to show a particular path through a welter of possibility (Beatty 2016). A subspecies is metanarrative, which is intended to interpret or explain life circumstances and bring meaning to isolated events by setting them within the context of an overarching pattern. A metanarrative typically offers a framework for structuring and justifying the beliefs and practices of individuals, groups, and societies. Throughout human history, metanarratives have been pervasive and are associated with religious, political, or social institutions that perpetuate asymmetric power relations between groups of people. This suggests that metanarratives might be less common in the realm of scientific inquiry where many of their aspects have been called into question, if not significantly undermined. However, their ubiquity might also indicate that metanarratives should be expected among

\footnotetext{
A. C. Love $(\bowtie)$

Department of Philosophy, Minnesota Center for Philosophy of Science, University of Minnesota, Minneapolis, MN, USA e-mail: aclove@umn.edu

(C) The Author(s) 2022

K. J. Clark, J. Koperski (eds.), Abrahamic Reflections on

Randomness and Providence, https://doi.org/10.1007/978-3-030-75797-7_7
} 
communities of scientists, even if they take on distinctive shapes and contours (Beatty 2017; Losos 2017). ${ }^{1}$

For more than two decades, a protracted debate has been waged over how to interpret the wider significance of fossils from the Burgess Shale and the Cambrian Explosion. On the side of contingency that emphasizes unpredictability, Stephen Jay Gould argued that if the "tape of life" was rerun, then the lineages that resulted would differ radically from what we find today (Gould 1989). One implication is that the human species is a happy accident, a pure gift of chance from the evolutionary process. On the side of convergence that emphasizes repeatability, Simon Conway Morris argued that if the "tape of life" was rerun, the lineages that resulted would be largely similar to what we now observe (Conway Morris 1998). A significant implication is that intelligence would still emerge from the evolutionary process (Conway Morris 2003). Although diametrically opposed, both sides provide an explanatory metanarrative with a basis in evolutionary biology seen specifically through the lens of paleontology and its efforts to reconstruct the history of life from the fossil record. Conway Morris and Gould set forth overarching interpretations of life circumstances that bring meaning (or not) to isolated evolutionary events by contextualizing them within a pattern of history which can structure and justify beliefs about what it means to be human.

A central inferential maneuver of these metanarratives is that the success of evolutionary science (primarily) and paleontology (in particular) justifies the perspective on offer. This move-from scientific success to general metaphysical conclusions about what the world is ultimately likeis common and has been scrutinized extensively by philosophers in the context of questions about scientific realism. An assumption pervading these analyses is that the relevant success is located in the performance of scientific theories or their component features, such as whether a theory has made novel predictions: "Scientific realism is a positive epistemic attitude towards the content of our best theories and models" (Chakravartty 2017). However, as Ian Hacking argued several decades ago, "One can believe in some entities without believing in any particular theory in which

\footnotetext{
${ }^{1}$ Metanarratives are not scientific theories. Although there can be implicit theories that structure and guide inquiry, there also are situations where metanarratives operate in science, such as by constraining explanatory options or as supposed outcomes of successful investigation. The latter possibility is in view here.
} 
they are embedded" (Hacking 1983, 29). Hacking concentrated on visualization practices in microscopy to illustrate this point, bequeathing to philosophy the memorable slogan in relation to electron microscopy: "if you can spray them then they are real" (23).

Assuming the sciences are a-if not the most-reliable way to learn about the way the world is, then the successes of science are a good place to work out the structures of reality (i.e., metaphysics). However, we know from history that scientists can be dramatically wrong. The successes of today could be the failures of tomorrow. Empirically successful theories of the past have subsequently been falsified and rejected. Why think anything different will obtain for current theories? Part of the motivation for shifting from theories to practices is that many practices have been stable across dramatic changes in scientific theories. For example, genetic approaches have been in use for more than 100 years despite major changes in our understanding of the nature of heredity and concept of the gene (Waters 2017). Practice-based knowledge is a distinct locus for scrutinizing the success of evolutionary science, and paleontology in particular.

Recent methodological innovations in paleontological practice, in combination with empirical work in evolutionary biology (Blount et al. 2018; Losos 2017), call into question whether either of the metanarratives put forward by Gould or Conway Morris is justified. These practices illustrate how analyzing fossils in terms of parts (traits) and wholes (e.g., organisms, lineages) advances our understanding of character evolution and suggest that global claims about the history of life, whether in terms of essential contingency or predictable convergence, are unwarranted (Hopkins and Lidgard 2012; Hunt et al. 2015; Lidgard and Love 2018). Do these successful practices harbor other metaphysical implications? Possibly, but in a much more piecemeal fashion than is conducive to metanarrative. Instead of an epic saga or metanarrative, successful scientific practices are better suited to circumscribed narrative genres, such as a short story. They seldom lead to global metaphysical conclusions of the kind that have been at stake in ongoing debates about the history of life. However, they can provide fodder for theological analysis and I explore some possible directions of inquiry related to implications of these successful paleontological practices for aspects of standard conceptions of divine providence. 


\subsection{Chance and Contingency Versus Convergence and Predictability in the History of Life}

Surviving rocks of the Ediacaran period ( 635-541 million years ago [mya]) and Cambrian period (541-485 mya) chronicle a complex evolutionary transformation, culminating with the appearance of Cambrian fossils that represent multicellular animals and exemplify characteristic features of extant phyla (Erwin and Valentine 2013). The appearance of these fossils in the Cambrian Explosion over a short span of geological time, and at this time and not earlier or later, constitutes an enduring evolutionary problem (Erwin et al. 2011; Marshall 2006; but see Wood et al. 2019). Several Cambrian localities of exquisite preservation contain large numbers of individuals in a wider array of taxa than normally observed and exhibit rare detail for both soft and hard tissues. The Burgess Shale in Canada (508 mya) is arguably the most famous of these (Briggs et al. 1994), especially because of beguiling arrangements of morphology, such as the five-eyed and stalk-mouthed arthropod Opabinia regalis.

Although ongoing research is helping to elaborate and refine multidisciplinary explanations of this distinctive event in Earth history, much of the controversy has revolved around what kind of meaning or wider significance the Cambrian Explosion, and Burgess Shale in particular, has for understanding who we are as humans. The competing evolutionary metanarratives of contingency (Gould 1989) and convergence (Conway Morris 2003) have dominated this discussion, both of which move from the success of evolutionary science and paleontology to metaphysical conclusions about what the world is ultimately like.

\subsubsection{Contingency}

Gould's argument for the contingency metanarrative begins with a thought experiment about what would happen if evolution "started over", especially at the dawn of animal life reflected in the Cambrian Explosion. It was framed in terms of a technology that has largely (though not wholly) been superseded: magnetic tape data storage.

I call this experiment "replaying life's tape." You press the rewind button and, making sure you thoroughly erase everything that actually happened, go back to any time and place in the past-say, to the seas of the Burgess Shale. Then let the tape run again and see if the repetition looks at all like 
the original. ... I believe that the reconstructed Burgess fauna, interpreted by the theme of replaying life's tape, offers powerful support for this different view of life: any replay of the tape would lead evolution down a pathway radically different from the road actually taken. (Gould 1989, 48, 51)

The phrase "view of life" is intentional as Gould is explicit in drawing out the metaphysical implications of this paleontological success: "This ... alternative represents no more nor less than the essence of history. Its name is contingency" (51). The invocation of essences signals a metaphysical picture:

This book is about the nature of history and the overwhelming improbability of human evolution under themes of contingency and the metaphor of replaying life's tape. It focuses upon the new interpretation of the Burgess Shale as our finest illustration of what contingency implies in our quest to understand the evolution of life. (51)

Three elements of Gould's argument need to be recognized. The first is that contingency is used in two distinct ways (Beatty 2006). One sense of contingency is unpredictability or contingency per se. If you stood at the origination point for the playing of the tape, the sheer number of possible combinations that could occur through time would make it impossible to predict the direction of evolution (unless you were an omniscient Laplacian demon). Hence, we get "the overwhelming improbability of human evolution." The second sense of contingency is causal dependence or the effect of a historical pathway (contingent upon). Current products of the evolutionary process, such as humans, are conditioned by a host of detailed prior states that were necessary to yield a particular outcome. This augments the metanarrative because the influence of causal history means any present outcome is unique or contingent upon many details of dependence that could have been different on many occasions by virtue of contingency per se.

The second element of Gould's argument is the contrast class to contingency. He frames two distinct and mutually exclusive possibilities for the outcome of replaying life's tape. Why did only a small number of phyla or major taxa persist compared with the many that arose in the early Cambrian period (at least on this reconstruction of the Burgess Shale)? The first possibility is that the survivors (including our ancestors) were much better adapted to their environments. If we replayed the tape over 
and over again, we would get similar outcomes (i.e., convergence arising from adaptive evolution to similar environments; see $\$ 2.3$ ). "If each replay strongly resembles life's actual pathway, then we must conclude that what really happened pretty much had to occur" (Gould 1989, 48). The second possibility is that the survivors (including our ancestors) were lucky, winning a lottery among equally, if differently, adapted forms. Replays of the tape would yield different outcomes, "results strikingly different from the actual history of life" (48). This contrast can be applied directly to thinking about human existence. Why did Pikaia - the first known chordate and possibly an ancestor of vertebrates, including humans-persist, rather than Opabinia? Gould affirms the second possibility: "replay the tape a million times from a Burgess beginning, and I doubt that anything like Homo sapiens would ever evolve again. ... Wind the tape of life back to Burgess times, and let it play again. If Pikaia does not survive in the replay, we are wiped out of future history" $(289,323) .^{2}$

A third element in Gould's argument is a different interpretation of patterns of diversity through the history of life. He accuses evolutionary biologists of harboring a default assumption that there is a gradual and steady increase of species diversity through evolutionary time (a cone of increasing diversity). However, the lottery-style survivorship of some major taxa rather than others in the Cambrian points to a different model of diversification-decimation followed by diversification - in which an initially large amount of diversity is severely pruned and followed by subsequent diversification occurring within surviving lineages. This illustrates the previous two elements because the decimation-diversification model accents both senses of contingency and aligns with the second interpretation of surviving lineages winning the evolutionary lottery and diversifying into many different and uniquely adapted forms.

These three elements-(1) two senses of contingency, (2) contingency and convergence as mutually exclusive options, and (3) the decimationdiversification model of diversity-together comprise Gould's argument that replaying life's tape supports an evolutionary metanarrative of contingency. This is a metaphysical conclusion based on the paleontological achievement of having reconstructed the Burgess Shale fossils, justifying the claim that they have implications for human existence. "The animals of

\footnotetext{
${ }^{2}$ Gould does not claim that Pikaia is actually ancestral in the human lineage. For literary purposes, he has it stand in for a small group of chordate taxa extant in the early Cambrian.
} 
the Burgess Shale are holy objects-in the unconventional sense that this word conveys in some cultures.... we greet them with awe because they are the Old Ones, and they are trying to tell us something" (Gould $1989,52)$.

\subsubsection{Convergence}

Simon Conway Morris, one of the paleontologists involved in reconstructing Burgess Shale fossils, agrees that the fossils have something to say, but disagrees about what they are trying to tell us. Conway Morris thinks the message affirms the first possibility of convergence-the independent evolution of similar traits due to similar environmental circumstances. If we replayed life's tape, we would get a very similar outcome.

The reason for discussing convergence here is that its recognition effectively undermines the main plank in Gould's argument on the role of contingent processes in shaping the tree of life. ... Contingency is inevitable, but unremarkable. It need not provoke discussion, because it matters not. There are not an unlimited number of ways of doing something. For all its exuberance, the forms of life are restricted and channelled.(Conway Morris 1998, 13)

Conway Morris went on to provide a systematic synthesis of convergence phenomena from different levels of organization across life's phylogenetic tree: "the recurrent tendency of biological organization to arrive at the same 'solution' to a particular 'need"' (Conway Morris 2003, xii). Icons such as the kiwi bird, which has well-developed senses of smell and hearing, a face covered with "whiskers," bones containing marrow instead of air sacs, and shaggy, hair-like plumage, help to illustrate how a common niche for ground animals in New Zealand-where there were no mammals-originally facilitated such an evolutionary outcome. The implication from the evolutionary metanarrative giving meaning to human existence is stated forthrightly in the subtitle ("Inevitable Humans in a Lonely Universe") and preface: "[my] aim is to argue that, contrary to received wisdom, the emergence of human intelligence is a nearinevitability" (xii).

Empirical warrant for Conway Morris's argument is the existence of recurring patterns in evolutionary outcomes across diverse taxa, whether it is the camera eyes of cephalopods and vertebrates, the farming practices 
of humans and ants, or the rodent-like features of the kiwi. These patterns show that the number of evolutionary possibilities is limited by the operation of natural selection in similar environments and therefore the explosion of combinatorics that Gould appealed to with contingency per se is rendered moot. The restrictions and channels exhibited by these patterns make it possible to predict many evolutionary outcomes.

The constraints we see on evolution suggest that underlying the apparent riot of forms there is an interesting predictability. This suggests that the role of contingency in individual history has little bearing on the likelihood of the emergence of a particular biological property. (Conway Morris $1998,139)$

These patterns also diverge from the expectations of both models of diversity in the history of life discussed by Gould. Instead of a gradual increase of diversity or an initial burst of diversity followed by substantial pruning, Conway Morris favors a rapid increase of diversity in the Cambrian followed by a slower general increase over time afterward (207). Notably, he does not take issue with the causal dependence thesis (contingent upon) because he acknowledges that the camera eye of a squid will be conditioned by its molluscan heritage in a way that differs from the camera eye of a primate.

Conway Morris, similar to Gould, is explicit in emphasizing that an argument is being made from our understanding of the Burgess Shalesuccessful paleontological science-to implications for what it means to be human.

The reality of convergence suggests that the tape of life, to use Gould's metaphor, can be run as many times as we like and in principle intelligence will surely emerge. ... we muddy the waters of the debate if we fail to acknowledge that the processes of evolution have metaphysical implications for us. (14)

However, the implications are dramatically different. For Gould, "perhaps we are only an afterthought, a kind of cosmic accident, just one bauble on the Christmas tree of evolution" (Gould 1989, 44). For Conway Morris, "there is inherent in our human situation the possibility of transcendence" (Conway Morris 1998, 14). 


\subsubsection{Contemporary Coda}

Since the initial articulation of these two evolutionary metanarratives, a number of relevant scientific developments have occurred (reviewed in Erwin 2016). These remind us that we should be cautious about drawing metaphysical implications from both successful scientific theories and practices because their fortunes can change. One example of this in the present context is a change in taxonomic methodology that prompted a revisionary understanding of the Burgess Shale fossils (Brysse 2008). The change occurred with the adoption of cladistic methods for reconstructing phylogenies within paleontology and included a key distinction between stem groups and crown groups. A crown group is a "monophyletic clade" (a group consisting of a species and all its descendants) of extant species that trace back to a last common ancestor and include extinct representatives derived from this common ancestor. A stem group is a "paraphyletic clade" (a group consisting of some but not all descendants of the last common ancestor); it contains extinct members of a monophyletic clade that are not part of the phylogenetic branch of the crown group. The common ancestor of the clade is not part of either group. This distinction makes it possible for there to be unique and distinctive features in a stem group (e.g., the five eyes and stalked mouth of Opabinia), even though by virtue of other traits (e.g., body segmentation) it is part of an extant major taxon (e.g., arthropods). "Since 1989, cladistic analyses have accommodated most of the problematic Cambrian taxa as stem groups of living taxa" (Briggs and Fortey 2005, 96; cf. Brysse 2008).

This change in taxonomic methodology and reclassification of Burgess Shale fossils undermined Gould's decimation-diversification model, which depended on interpreting the weird wonders as distinct phyla or major groups that went extinct in the Cambrian. However, this was not as central as the other elements of Gould's argument (two senses of contingency and contingency vs. convergence as mutually exclusive options). These remained intact and inspired a wide range of empirical tests (Blount et al. 2018). Most prominent among these are experimental evolutionary studies (e.g., Good et al. 2017). In these experiments, replicate populations are propagated under highly controlled conditions (e.g., with a small set of known environmental variables and already characterized genotypes). These populations are monitored for evolutionary changes in gene frequencies or the origin of an ability to metabolize a novel resource. Causal dependence (history), contingency per se (chance), and deterministic 
processes (natural selection/convergence) can be evaluated quantitatively and repeatedly, effectively running life's tape again and again on small scales. Adjustments can be made in the initial conditions and environmental circumstances modified in a precise manner. Biologists can scrutinize what happened at a particular stage of the experiment and possibly design additional experiments to test new hypotheses.

Other relevant empirical demonstrations involve natural experiments, such as evolutionary patterns associated with the repeated colonization of islands by Anolis lizards after severe weather events (Losos 2017; Stroud and Losos 2016), as well as documentation of repeatability in genotypic and phenotypic evolution (Orgogozo 2015). Overall, the message emerging from these different scientific studies does not support either evolutionary metanarrative. Both contingency and convergence are present heterogeneously across taxa undergoing evolutionary change in different traits at a variety of levels of organization. ${ }^{3}$ If there is any tendency across the history of life, evolutionary repeatability and predictability are more reliably (though not exclusively) observed in closely related lineages, whereas contingency is more typical (though not universal) as historical depth, phylogenetic distance, and ecological difference increase (Blount et al. 2018). However, these experimental studies are not primarily about the fossil record and have focused on microevolutionary processes. Whether that means their results should count more or less (or the same) in the context of evaluating evolutionary metanarratives is an open point of debate (Desjardins 2016; Turner 2011). At a minimum, it is profitable to see how the evolutionary metanarratives are undermined by actual paleontological practices—studies of the fossil record.

\subsection{Chance and Selection in the Fossil Record: Successful Paleontological Practices}

Paleontological practices have been in the foreground of Burgess Shale discoveries from the beginning. Infamously, the iconic taxon Hallucigenia sparsa was reconstructed incorrectly (Brysse 2008). Related difficulties in reconstructing and classifying Burgess Shale fossils resulted from a

\footnotetext{
3 “Although Gould's ideas on contingency have stimulated a great deal of productive work, his view that contingent effects were pervasive throughout evolution remains debatable.... Clearly, evolution can be both contingent and deterministic, and often in complicated and fascinating ways" (Blount et al. 2018, 8).
} 
standard problem for paleontology: the differential preservation or colocation of organismal parts. For example, Anomalocaris canadensis was first described based on a headless carapace in 1892 (Brysse 2008). Two other supposed fossil animals, the jellyfish Peytoia and the sponge Laggania, turned out to be isolated body parts from Anomalocaris. The situation was resolved only after a more complete specimen was recovered in 1981. This showed that the original "carapace" was a disarticulated frontal feeding appendage, the amorphous "sponge" a portion of the body, and the circular "jellyfish" its mouth. However, in many cases, there is not a complete specimen that resolves all of these parts into clarified locations within an organism and nearly all fossil specimens are incomplete (i.e., based off of a partial set of fossilized traits). This points us to a significant aspect of how paleontologists operate as scientists.

All scientific practice involves using proxies - measurements of particular properties that stand in for something else. For example, phylogenetic systematic methods encourage treating taxa (wholes) as aggregates of traits (parts). In paleontological analyses, hard body parts are more available and abundant than soft body parts. The hard body parts serve as proxies for the lineages studied, frequently in the absence of any preserved soft body parts. This is applicable to both classification and testing hypotheses about chance and natural selection in the fossil record. When scientists are interested in evaluating questions about whether a lineage is convergent (due to natural selection) or contingent (due to chance factors), then an ambiguity can emerge between and among morphological and molecular parts and whole organisms or genomes of a lineage or clade that contain these parts. Does one body part (e.g., a skeletal element) represent the evolutionary dynamics of other characters in the lineage (e.g., a genomic element)? This is common practice in paleontology: single size and shape characters are often taken to represent a species or lineage in quantitative studies of evolutionary modes (Hopkins and Lidgard 2012).

Newer analyses where multiple characters are recorded for the same species or lineage frequently distinguish different evolutionary modes for different characters (Hopkins and Lidgard 2012; Hunt et al. 2015; Voje et al. 2018). This can be illustrated with a hypothetical lineage of fossil fish (Fig. 7.1). Many characters are available to represent the lineage. Of those available, a subset is selected to be measured and represent the lineage (in this case, eye width, tail fin length, and pectoral fin length). After doing the quantitative analysis, each of the three characters is best accounted for 

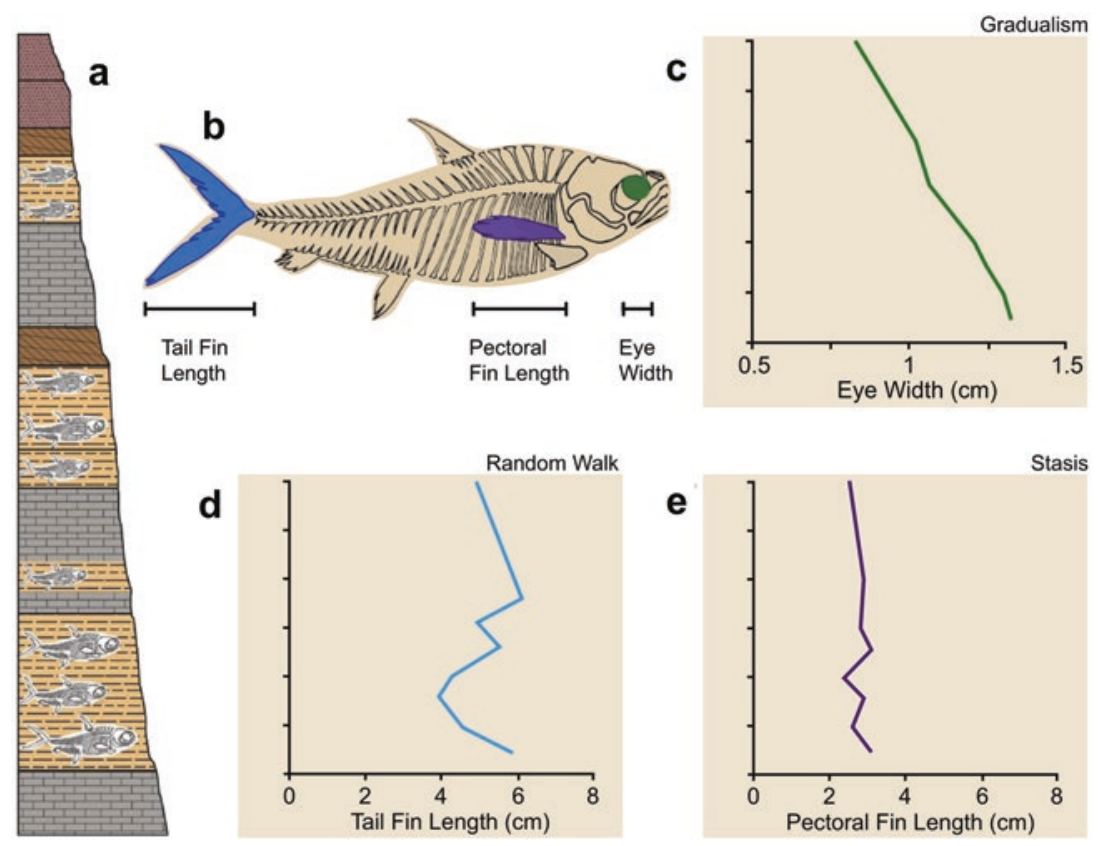

Fig. 7.1 Distinct evolutionary trajectories of different traits in a hypothetical fossil fish lineage exemplify results from hundreds of published studies (Hopkins and Lidgard 2012; Hunt et al. 2015). (a) Population samples are taken at successive intervals from sedimentary layers that contain fossils. (b) Characters are measured for each sample. Different evolutionary modes are seen in character trajectories plotted against stratigraphic positions for eye width (c), tail fin length $(\mathbf{d})$, and pectoral fin length (e). Illustration: Monica Jurik. (Source: Lidgard and Love (2018). Reproduced by kind permission of Oxford University Press on behalf of the American Institute of Biological Sciences under the terms of the Creative Commons Attribution Non-Commercial License [http://creativecommons.org/ licenses/by-nc/4.0/])

by a different model of evolutionary change: gradualism for eye width, random walk for tail fin length, and stasis for pectoral fin length. If we had only used a single size or shape character, it would have generated a different perspective on the evolutionary trajectory of the fossil fish lineage. More abstractly, there is a complicated relationship between parts and wholes through evolutionary time (Losos 2017). 
When this type of analysis is performed on marine invertebrate taxa with good preservation and well-sampled vertical distributions of fossils in the geological column, single traits frequently show different evolutionary modes in the same sequence (e.g., chance, then selection, then chance). This diachronic complexity of evolutionary change increases as a greater number of traits is measured. Mosaic patterns of trait evolution are common in the fossil record. Researchers can empirically detect both selection (in the form of directional change or stasis) and chance (in the form of a random walk), and both of these are present heterogeneously across the measured characters in taxa undergoing evolutionary change. Additionally, sequences of fossils with more representatives (i.e., more samples in a sequence) are more likely to display complex modes of evolutionary change (e.g., random walk followed by stasis) rather than simple modes (e.g., random walk alone or stasis alone) (Hunt et al. 2015). Thus, the same organismal part is subject to varying dynamics of evolutionary change over time in a lineage rather than being primarily the result of a single evolutionary mode (e.g., directional change).

Although there is an inevitable degree of uncertainty in using models to analyze these complex patterns, and these methods have biases that lead to particular kinds of errors (Voje 2016, 2018; Voje et al. 2018), the primary conclusion based on their success is unaffected. For example, in some cases the best model identified according to the criteria does not adequately describe the trait dynamics in a fossil time series (Voje 2018). However, the aggregated result of heterogeneous and complex modes without one predominating evolutionary trajectory remains. Overall, these methodological innovations in paleontological practice call into question the evolutionary metanarratives advanced by Gould and Conway Morris. And this conclusion is congruent with the consensus arrived at through natural and laboratory experimental studies of chance and natural selection $(\$ 2.3)$.

In a comprehensive review of the question of contingency versus convergence in relation to the Burgess Shale and Cambrian Explosion, paleobiologist Doug Erwin captures this consilience of different perspectives acutely.

It seems unlikely that there will be any general answer to questions over the role of contingency versus necessity in evolution, either with the Burgess Shale fossils and the Cambrian radiation specifically, or more generally in the history of life, in large part because at such a coarse level the question is 
wrongly specified. The relative importance of contingency depends upon whether one is interested in molecular processes, development, phenotype, or macroevolutionary patterns, and the answer may differ at these different levels, even for the same event. (Erwin 2016, 297)

This synthetic conclusion accents two key points about the adequacy of metanarratives for evolutionary history. ${ }^{4}$ The first is that empirical research yields a mixed message about the predominance of evolutionary mode: there is no "general answer to questions over the role of contingency versus necessity in evolution." A framing of the two evolutionary metanarratives as mutually exclusive and exhaustive options is undermined. To retain an inference from successful science to metaphysical implication, as is the desire in these evolutionary metanarratives, other options must be formulated or the enterprise disbanded (e.g., because we cannot formulate relevantly precise empirical models for the history of life). Second, these evolutionary metanarratives frame the question too coarsely. When the units of interest are more precisely specified (e.g., molecular processes vs. macroevolutionary patterns) - a move justified by the successful paleontological practices of modeling evolutionary change for traits instead of organisms or lineages (Hopkins and Lidgard 2012; Hunt et al. 2015) the patterns observed may be different and therefore new kinds of answers might become available (Lidgard and Love 2018). A natural question is whether different metaphysical implications might be warranted in light of this heterogeneous architecture of successful science.

\subsection{Potential Implications for Divine Providence?}

Does the argument from successful paleontological practices in reconstructing evolutionary dynamics based on the fossil record imply something for conceptions of divine providence-a very different kind of metaphysical implication? This question is appropriate since the two competing metanarratives both speak to what the history of life implies for the human species. However, it is not possible to review the entirety of possibilities for how divine providence has been understood historically (Flint

\footnotetext{
${ }^{4}$ One might resist drawing general conclusions from Burgess Shale fossils and the Cambrian Explosion because they are deemed non-representative. This would require deciding whether there are any independent, comparable cases that might validate their representativeness. Natural candidates might be recoveries after mass extinctions or the invasion of "unoccupied" habitats, such as moving onto land or colonizing islands.
} 
2010; Jowers 2011; Tracy 2010) or in relation to the sciences (Clark 2014, ch. 2; Koperski 2015, ch. 4; Saunders 2002). Instead, I focus on discussions that have been motivated by contrasting evolutionary metanarratives from Gould and Conway Morris in theological contexts that speak to the metaphysical question of divine action generally and providence in particular. ${ }^{5}$

Consider a recent paper that tries to navigate between these evolutionary metanarratives by arguing that there is unpredictability due to randomness in the world, but this is constrained within patterns of convergence due to natural selection (McCall 2019). This discussion is not informed by the scientific developments and successful paleontological methods described above. As a consequence, it retains a strict dichotomy between contingency and convergence, while seeking a hybrid conceptualization that adopts the major features of each metanarrative. The result is unclear and uninformative: how much randomness is there and how tightly is it constrained within patterns of convergence? These types of arguments, with explicit dependence on the dichotomy between contingency and convergence, have been advanced by a variety of authors: "The alternative positions are set out in Gould's Wonderful Life (1989) and Conway Morris' Life's Solution (2003). ... One or other of them must be mistaken" (Bartholemew 2008, 186-7). They are apropos in the context of evolutionary metanarratives that propose overarching interpretations of historical patterns to inform what it means to be human.

The first possibility is that there is no metaphysical implication of scientific success relevant for understanding divine action in the world. If every conception of divine providence is a metanarrative, then the heterogeneous results of empirical studies exemplified in paleontological analyses of character evolution could be uniformly uninformative. For example, if providence is understood broadly as the claim that "the events of our world, no matter how chaotic or disturbing they might appear, unfold precisely according to the plan established eternally by our all-knowing and loving sovereign" (Flint 2010,329), then a variety of combinations of chance (contingency per se), history (contingent upon), and natural selection (convergence) could be accommodated within such an overarching

\footnotetext{
${ }^{5}$ Metaphysical implications could be either positive or negative (e.g., providing reasons for or against a particular conception), but also can include the introduction of new questions (e.g., a previously unrecognized puzzle about how these successful practices comport with a particular conception of providence).
} 
plan. From our perspective, even though there is no reason based on paleontological practice to see the arrival of the human species as either sheer accident or deterministically predictable, there also is no reason to think that one combination of chance, history, and natural selection means something different from another. Successful scientific practice offers nothing that discriminates between understanding one sequence of historical events as going according to plan and another not.

What happens if we introduce concepts and distinctions from discussions of divine providence, such as the difference between special divine action (SDA) and general divine action (GDA)? The former comprises "those actions of God that pertain to a particular time and place in creation as distinct from another," whereas the latter can be characterized as "those actions of God that pertain to the whole of creation universally and simultaneously" (Saunders 2002, 21). Many putative occurrences of SDA are littered throughout the Tanakh, such as the account of Egyptian plagues prior to the Hebrew exodus. Exemplars of GDA might be regularities associated with "laws of nature" such as gravitational attraction. Both SDA and GDA are pertinent to providence, though distinguishing the two cleanly is not easy. Assuming God could intervene or act in the world, then successful paleontological practices associated with reconstructing evolutionary change in the fossil record suggest there is a wide latitude for achieving particular outcomes (e.g., humanoid species) in the history of life through judicious combinations of chance, history, and natural selection. Without a predominant deterministic trend (such as convergence) or indeterministic lack of pattern (due to different forms of contingency), a plethora of options remain. And, even if one trend was empirically established as predominant, it is not clear that it would speak for or against any conception of SDA (Koperski 2015, ch. 4). Thus, this permissive inference is weak (i.e., there appears to be no contradiction) and arguably collapses into no metaphysical inference. GDA seems less relevant because the causal processes operative in geological history are not typically thought of as acting "universally and simultaneously" across all that exists. However, if GDA is cashed in terms of environmental changes, mutations, and natural selection (inter alia) operating through geological history, then we recover the same weak inference of consistency because the lack of an overarching signal in the fossil record makes it difficult to meaningfully detect providence in contrast to some other signature (or lack thereof), such as genuine randomness. 
Another way to probe possible metaphysical implications from successful paleontological practice is to look for congruence or incongruence with major options for conceptualizing divine providence. One optiondivine omnicausality - is associated with traditional conceptions of providence from thinkers such as Augustine, Calvin, and Warfield, as well as many in the Muslim tradition (Helseth in Jowers 2011, ch. 1). On this view, God is the ultimate or primary cause of all events such that nothing occurs by "chance" (i.e., the causal structure of the world is fully ordered and arranged). However, secondary causes are genuine rather than epiphenomenal. These secondary causes are real but absolutely dependent on God's preservational, primary activity. Neither causal dependence (contingent upon) nor convergence (natural selection) pose difficulties on this view because both pertain to the realm of secondary causes. Chance (contingency per se) might appear incongruent with this option but recall that contingency is cashed out as unpredictability (i.e., epistemic chance). Therefore, it need not be a challenge for divine foreknowledge (or a Laplacian demon), which can handle the explosion of possible combinations, or if God's relation to time is such that all of world and universal history is "seen" simultaneously from an atemporal vantage point (Ganssle 2001).

Divine knowledge handling an explosion of future possibilities is especially suited to divine omnidirectionality, which holds that God has hypothetical knowledge of all counterfactuals about what would happen in any circumstance (Craig in Jowers 2011 , ch. 2). On this view, so-called secondary causes need not depend on God's primary causation for their existence, but the causal structure of the world remains fully ordered and arranged because divine knowledge can map out the complete space of possibilities from any chosen set of initial conditions (fully embracing both senses of contingency). The complex evolutionary outcomes of chance, history, and selection do not surprise God. On a third view, sometimes labeled "open theism," the causal structure of the world is not fully ordered and arranged; there is no future causal order to foreknow (Boyd in Jowers 2011, ch. 4). In this case, there is not a "fixed" future of possible events for God to know counterfactually in advance. Thus, the actual causal path taken through history is only learned by God as it plays out. Whether this would lead to something broadly humanoid is less clear and any necessary exercise of omnipotence along the way to secure this type of outcome might need to be much more substantial. 
Finally, we can contemplate whether there are any ramifications from successful scientific practice for standard objections that drive differences in conceptions of divine providence. The most prominent of these are the problem of freedom and the problem of evil (Flint 2010). If divine providence involves meticulous foreknowledge, which is embedded in the clause "unfold precisely according to the plan established eternally by our all-knowing ... sovereign," then free will appears inconsistent with these commitments (at least according to open theists). If things "unfold precisely," then God knows what I will do beforehand. This removes the possibility of me doing otherwise (since God could not be wrong in what is foreknown). However, in the present case, the question of freedom seems irrelevant, at least if we are attributing free will primarily to humans. That God could somehow "steer" evolutionary history through complex combinations of chance, history, and natural selection based on foreknowledge does not threaten human freedom; one might even argue that it makes it possible. Exercises of omnipotence are not prima facie implausible since the primary reason against their use is the violation of genuine agential choice, which might be a non-issue for Burgess Shale animals (among others). Regarding the problem of evil, especially in its evidentiary form, it is not clear that an evolutionary history governed primarily by natural selection versus one more commensurate with the empirical evidence (i.e., heterogeneous, complex combinations) would pose a greater threat in augmenting or diminishing the amount of purported evil present in the world. However, many argue that increased SDA exacerbates the problem of evil since it raises the specter of why God doesn't more reliably remove or mitigate evil occurrences (Saunders 2002).

One might be concerned that these inferential offerings are meager. However, they help highlight one overlooked possibility. Although providence is typically conceptualized as a combination of SDA and GDA, many sacred texts associated with ideas about divine providence in Judaism, Christianity, and Islam are directed at particular people in specific circumstances (e.g., the story of Abraham discovering a ram in the thicket, thereby making it possible to sacrifice something other than his own son). If our most robust and empirically grounded analyses of the fossil record tell complex stories about the interplay between chance, history, and natural selection, then we might seek to detail that story more locally for the geological sequence relevant primarily to the human species (not the entire history of life). Instead of worrying about Opabinia or Pikaia, we might concentrate our attention on Homo. Unfortunately, as has been 
noted by many, the fossil record (and general empirical information available) for our lineage is notoriously incomplete (Antón et al. 2014). And since our most successful paleontological practices yield stable empirical generalizations precisely when there are more samples available, it is unlikely that we can (at this time) apply them with profit to the human fossil record (i.e., ascertaining the signature of chance, history, or selection for particular traits).

Yet we should not lose sight of the fact that there could be possible metaphysical implications of successful paleontological practice. If the fossil record for Homo was sufficiently representative (i.e., contained enough sample sequences), then the application of successful practices for reconstructing character evolution could have metaphysical implications for traits in the human lineage. The detection of a particular evolutionary mode for a character, such as bipedality showing an unambiguous random walk over millions of years, might suggest new reflections on what it means to be human (i.e., bipedality might be less central or "accidental" to our humanity). Only time will tell if we arrive at an adequate empirical situation in terms of fossil record data to ascertain this possibility. However, an emphasis on successful scientific practices where the empirical situation is better could point us to distinct records of the past where different kinds of traits can be analyzed in sufficient detail, such as lithic tools or other cultural artifacts (Tostevin 2019). Instead of paleontology, successful archeological practice might offer a more illuminating route to identify metaphysical implications.

\subsection{Conclusion}

My analysis has ignored a number of issues related to contingency and convergence in evolutionary biology. What exactly constitutes convergence (Pearce 2012; Powell 2012)? The inability to distinctly specify convergence makes it difficult to claim that it is more or less predominant in the history of life. Similar concerns exist for contingency (Desjardins 2016; Turner 2011), as well as how best to characterize its evolutionary sources and effects, such as mass extinctions and adaptive radiations (McConwell and Currie 2017; McConwell 2019). In particular, there are good theoretical arguments for taking both contingency and convergence as domain relative in order to sufficiently distinguish them and compare their relative importance (Lewis 2018). Although it would require explicit demonstration, this argument is congruent with the conclusions about 
character evolution drawn from successful paleontological practice, which are domain relative since the relevant modal profiles are in the empirical analysis. I also have ignored substantial empirical questions about the nature and status of directional trends in the fossil record and their connection to contingency or convergence (Huang et al. 2015).

Both Gould and Conway Morris offer metanarratives of ultimate reality through divergent interpretations of the fossil record. These visions are akin to epic sagas that provide a global interpretation of evolution and the history of life on earth, from origins to apocalypse. The heroic deeds and adventures of the saga are either due to contingency or convergence over extended periods of time, with an accent on the achievements of these heroes at special junctures, such as the Burgess Shale and Cambrian Explosion. We noted at the outset that our propensity for narrative, and metanarrative in particular, means we should not be surprised at finding such attempts in the halls of science (Beatty 2017). They fit within the move from scientific success to metaphysical conclusions about what the world is ultimately like.

However, subsequent successes of paleontological analyses of character evolution in the fossil record demonstrate that neither epic saga is warranted. Once the methodological shift of looking at parts instead of wholes is made, researchers find empirical signatures of both selection (in the form of directional change or stasis) and chance (in the form of a random walk), and both of these are present heterogeneously across the measured characters in taxa undergoing evolutionary change. One character can be under directional selection, while another displays a random walk at the same point in a sequence; a character can be under directional selection at one point in a sequence, while the same character is subject to a random walk at a later point in the sequence. Empirical studies inspired by Gould's image of replaying the tape of life have yielded a similar conclusion: "evolution can be both contingent and deterministic, and often in complicated and fascinating ways" (Blount et al. 2018,8). The original framing of the question is a false dichotomy (Losos 2017). "It seems unlikely that there will be any general answer to questions over the role of contingency versus necessity in evolution, either with the Burgess Shale fossils and the Cambrian radiation specifically, or more generally in the history of life" (Erwin 2016, 297).

The metaphysical implications of successful paleontological practices for conceptions of divine providence are unclear, in part because conceptions of providence are intended as metanarratives of divine action. Since 
the evolutionary metanarratives of Gould and Conway Morris break down, the connections between successful paleontological analyses of character evolution and understandings of divine providence are, if anything, piecemeal. ${ }^{6}$ This piecemeal inferential potential leaves many options open. Apart from this permissiveness, we identified the possibility that empirically grounded analyses of the human fossil record might tell complex but compact stories about the interplay between chance, history, and natural selection in our own lineage. Although the necessary representation in the fossil record is currently lacking, which means our best paleontological practices cannot be deployed, this possible metaphysical implication and the structure of the argument point toward other successful practices, such as from archeology, which might speak more directly to what it means to be human.

Assuming the successes of the sciences are a good place to work out the ultimate structure of reality and keeping in view appropriate concerns derived from the history of science, we might draw a different kind of lesson. The metaphysical implications available from the sciences are not characterized most aptly in terms of metanarratives or epic sagas. Instead, the implications are suited to a different narrative form, such as a short story. A short story has a fully developed theme but is significantly shorter and less elaborate than genres of longer form, whether novels or epic sagas. Short stories might have less appeal for those seeking an overarching integration with systematic theology, but it is worth highlighting that short stories are a common genre in literature from different religious traditions. Thus, there may be a novel basis for exploring metaphysical implications from successful science within the context of these other genres embedded within theological understandings of diverse communities.

Do the exceptionally preserved fossils found in the Burgess Shale tell us something about chance, contingency, evolution, and history? Yes, though not in the form of an epic saga that Gould or Conway Morris argued for; instead, successful paleontological practices point toward rich short stories that are both heterogeneous and more circumscribed. Do the Burgess Shale fossils imply that we are here simply by chance or instead a

${ }^{6}$ This is does not rule out the possibility of metanarratives based on successful scientific practices, nor does it impugn the search for metanarratives per se. However, it is evidence that evolutionary metanarratives based on the fossil record are implausible, including but not limited to those of Conway Morris and Gould. 
predictable outcome? No, but both options in this dichotomy are evolutionary narratives of comprehensive scope. There is much we can learn about chance, history, and predictability from the themes of the short stories that emerge out of successful paleontological practices involving the empirical study of evolutionary modes for traits in the fossil record. The Old Ones might be trying to tell us something, but we need to adjust our expectations before we can hear what they are saying.

Acknowledgments I am grateful to team members on the project "Abrahamic reflections on science and religion" for their feedback on a version of this material presented at a working session in Casablanca in June 2019. I also received useful comments from those in attendance at my public lecture "Chance, Evolution, and the Burgess Shale" delivered at the Whyte Museum of the Canadian Rockies in Banff, Alberta, Canada (June 2017), where a very early iteration of this material was first aired. Finally, Kelly Clark, Max Dresow, Jeff Koperski, and Scott Lidgard read earlier versions of the manuscript and provided substantial comments. I appreciate their insights and criticisms while explicitly noting that their assistance does not constitute an endorsement of my thesis.

\section{BIBLIOGRAPHY}

Antón, Susan C., Richard Potts, and Leslie C. Aiello. 2014. Evolution of Early Homo: An Integrated Biological Perspective. Science 345: 1236828.

Bartholemew, David J. 2008. God, Chance, and Purpose: Can God Have It Both Ways? New York: Cambridge University Press.

Beatty, J. 2006. Replaying Life's Tape. Journal of Philosophy 103 (7): 336-362.

- 2016. What Are Narratives Good For? Studies in the History and Philosophy of Biological and Biomedical Sciences 58: 33-40.

- 2017. Narrative Possibility and Narrative Explanation. Studies in History and Philosophy of Science 62: 31-41.

Blount, Zachary D., Richard E. Lenski, and Jonathan B. Losos. 2018. Contingency and Determinism in Evolution: Replaying Life's Tape. Science 362: eaam5979.

Briggs, Derek E.G., and Richard A. Fortey. 2005. Wonderful Strife: Systematics, Stem Groups, and the Phylogenetic Signal of the Cambrian Radiation. Paleobiology 31: 94-112.

Briggs, Derek E.G., Douglas H. Erwin, and Frederick J. Collier. 1994. The Fossils of the Burgess Shale. Washington/London: Smithsonian Institution Press.

Brysse, Keynyn. 2008. From Weird Wonders to Stem Lineages: The Second Reclassification of the Burgess Shale Fauna. Studies in the History and Philosophy of Biological and Biomedical Sciences 39: 298-313. 
Chakravartty, Anjan. 2017. Scientific Realism. In The Stanford Encyclopedia of Philosophy (Summer 2017 Edition), ed. Edward N. Zalta. https://plato.stanford.edu/archives/sum2017/entries/scientific-realism/

Clark, Kelly J. 2014. Religion and the Sciences of Origins: Historical and Contemporary Discussions. New York: Palgrave Macmillan.

Conway Morris, Simon. 1998. The Crucible of Creation: The Burgess Shale and the Rise of Animals. New York: Oxford University Press.

- 2003. Life's Solution: Inevitable Humans in a Lonely Universe. New York: Cambridge University Press.

Desjardins, Eric. 2016. Contingent Evolution: Not by Chance Alone. In Chance in Evolution, ed. Grant Ramsey and Charles H. Pence, 223-243. Chicago: University of Chicago Press.

Erwin, Douglas H. 2016. Wonderful Life Revisited: Chance and Contingency in the Ediacaran-Cambrian Radiation. In Chance in Evolution, ed. Grant Ramsey and Charles H. Pence, 277-298. Chicago: University of Chicago Press.

Erwin, Douglas H., and James V. Valentine. 2013. The Cambrian Explosion: The Construction of Animal Biodiversity. Greenwood: Roberts.

Erwin, Douglas H., Marc Laflamme, Sarah M. Tweedt, Erik A. Sperling, Davide Pisani, and Kevin J. Peterson. 2011. The Cambrian Conundrum: Early Divergence and Later Ecological Success in the Early History of Animals. Science 334: 1091-1097.

Flint, Thomas P. 2010. Providence. In A Companion to Philosophy of Religion, ed. Charles Taliaferro, Paul Draper, and Philip L. Quinn, 2nd ed., 329-336. Malden: Blackwell Publishing.

Ganssle, Gregory E., ed. 2001. God and Time: Four Views. Downers Grove: Intervarsity Press.

Good, Benjamin H., Michael J. McDonald, Jeffrey E. Barrick, Richard E. Lenski, and Michael M. Desai. 2017. The Dynamics of Molecular Evolution over 60,000 Generations. Nature 551: 45-50.

Gould, Stephen J. 1989. Wonderful Life: The Burgess Shale and the Nature of History. New York: W.W. Norton \& Company.

Hacking, Ian. 1983. Representing and Intervening: Introductory Topics in the Philosophy of Natural Science. Cambridge: Cambridge University Press.

Hopkins, Melanie J., and Scott Lidgard. 2012. Evolutionary Mode Routinely Varies Among Morphological Traits Within Fossil Species Lineages. Proceedings of the National Academy of Sciences 109: 20520-20525.

Huang, Shan, Kaustuv Roy, James W. Valentine, and David Jablonski. 2015. Convergence, Divergence, and Parallelism in Marine Biodiversity Trends: Integrating Present-Day and Fossil Data. Proceedings of the National Academy of Sciences 112: 4903-4908.

Hunt, Gene, Melanie J. Hopkins, and Scott Lidgard. 2015. Simple Versus Complex Models of Trait Evolution and Stasis as a Response to Environmental Change. Proceedings of the National Academy of Sciences 112: 4885-4890. 
Jowers, Dennis W., ed. 2011. Four Views on Divine Providence. Grand Rapids: Zondervan.

Koperski, Jeffrey. 2015. The Physics of Theism: God, Physics, and the Philosophy of Science. Malden: Wiley Blackwell.

Lewis, Cory T. 2018. The Domain Relativity of Evolutionary Contingency. Biology and Philosophy 33: 25.

Lidgard, Scott, and Alan C. Love. 2018. Rethinking Living Fossils. Bioscience 68: 760-770.

Losos, Jonathan B. 2017. Improbable Destinies: Fate, Chance, and the Future of Evolution. New York: Riverhead Books.

Marshall, Charles R. 2006. Explaining the Cambrian "Explosion" of Animals. Annual Review of Earth and Planetary Science 34: 355-384.

McCall, Bradford. 2019. The God of Chance and Purpose. Theology and Science 17: 133-142.

McConwell, Alison K. 2019. Contingency's Causality and Structural Diversity. Biology and Philosophy 34: 26.

McConwell, Alison K., and Adrian Currie. 2017. Gouldian Arguments and the Sources of Contingency. Biology and Philosophy 32: 243-261.

Orgogozo, Virginie. 2015. Replaying the Tape of Life in the Twenty-First Century. Interface Focus 5: 20150057.

Pearce, Trevor. 2012. Convergence and Parallelism in Evolution: A Neo-Gouldian Account. British Journal for the Philosophy of Science 63: 429-448.

Powell, Russell. 2012. Convergent Evolution and the Limits of Natural Selection. European Journal for Philosophy of Science 2: 355-373.

Saunders, Nicholas. 2002. Divine Action and Modern Science. New York: Cambridge University Press.

Stroud, James T., and Jonathan B. Losos. 2016. Ecological Opportunity and Adaptive Radiation. Annual Review of Ecology, Evolution, and Systematics 47: 507-532.

Tostevin, Gilbert B. 2019. The Materiality of Cultural Transmission and the Intersection of Paleolithic Archaeology with Cultural Evolutionary Theory. In Beyond the Meme: Development and Structure in Cultural Evolution, ed. Alan C. Love and William C. Wimsatt, 311-364. Minneapolis: University of Minnesota Press.

Tracy, Thomas F. 2010. Divine Action. In A Companion to Philosophy of Religion, ed. Charles Taliaferro, Paul Draper, and Philip L. Quinn, 2nd ed., 308-314. Malden: Blackwell Publishing.

Turner, Derek D. 2011. Gould's Replay Revisited. Biology and Philosophy 26: 65-79.

Voje, Kjetil L. 2016. Tempo Does Not Correlate with Mode in the Fossil Record. Evolution 70: 2678-2689. 
2018. Assessing Adequacy of Models of Phyletic Evolution in the Fossil Record. Methods in Ecology and Evolution 9: 2402-2413.

Voje, Kjetil L., Jostein Starrfelt, and Lee Hsiang Liow. 2018. Model Adequacy and Microevolutionary Explanations for Stasis in the Fossil Record. American Naturalist 191: 509-523.

Waters, C. Kenneth. 2017. No General Structure. In Metaphysics of Science: New Essays, ed. Matthew H. Slater and Zanja Yudell, 81-107. New York: Oxford University Press.

Wood, Rachel, Alexander G. Liu, Frederick Bowyer, Philip R. Wilby, Frances S. Dunn, Charlotte G. Kenchington, Jennifer F. Hoyal Cuthill, Emily G. Mitchell, and Amelia Penny. 2019. Integrated Records of Environmental Change and Evolution Challenge the Cambrian Explosion. Nature Ecology o Evolution 3: 528-538.

Open Access This chapter is licensed under the terms of the Creative Commons Attribution 4.0 International License (http://creativecommons.org/licenses/ by $/ 4.0 /$ ), which permits use, sharing, adaptation, distribution and reproduction in any medium or format, as long as you give appropriate credit to the original author(s) and the source, provide a link to the Creative Commons licence and indicate if changes were made.

The images or other third party material in this chapter are included in the chapter's Creative Commons licence, unless indicated otherwise in a credit line to the material. If material is not included in the chapter's Creative Commons licence and your intended use is not permitted by statutory regulation or exceeds the permitted use, you will need to obtain permission directly from the copyright holder.

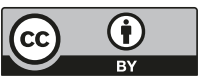

